\title{
Texture Analysis of Cold Rolled and Annealed Aluminum Alloy Produced by Twin-roll Casting
}

\author{
Juliana de Paula Martins ${ }^{\mathrm{a} *}$, André Luis Moreira de Carvalho ${ }^{\mathrm{b}}$, Angelo Fernando Padilha \\ ${ }^{a}$ Engenharia Química, Universidade Tecnológica Federal do Paraná - UTFPR, \\ Av Monteiro Lobato, s/n, Km 4, CEP 84016-210, Ponta Grossa, PR, Brazil \\ ${ }^{b}$ Departamento de Engenharia de Materiais, Universidade Estadual de Ponta Grossa - UEPG, \\ Av. General Carlos Cavalcanti, 4748, CEP 84030-900, Ponta Grossa, PR, Brazil \\ 'Departamento de Engenharia Metalúrgica e de Materiais - PMT, \\ Escola Politécnica, Universidade de São Paulo - USP, \\ Av. Prof. Mello Moraes, 2463, CEP 05508-900, São Paulo, SP, Brazil
}

Received: June 27, 2011

\begin{abstract}
A $7.4 \mathrm{~mm}$ thick strip of 3003 aluminum alloy produced by the industrial twin-roll casting (TRC) process was homogenized at $500{ }^{\circ} \mathrm{C}$ for 12 hours, after which it was cold rolled in two conditions: 1) to reduce the strip's thickness by $67 \%$, and 2) to reduce it by $91 \%$. The alloy was annealed at $400{ }^{\circ} \mathrm{C}$ for 1 hour in both conditions. The results revealed that a rotated cube texture, the $\{001\}<110>$ component, predominated in the as-cast condition and was transformed into brass, copper and $\mathrm{S}$ type textures during the cold rolling process. There was practically no difference between the deformation textures at the two thickness reductions.
\end{abstract}

Keywords: aluminum alloys, Al-Mn-Fe-Si, twin-roll continuous casting, texture

\section{Introduction}

The twin-roll casting (TRC) process produces coilable strip directly from the melt by combining casting and hot rolling into a single step ${ }^{1,2}$. In TRC, molten metal is fed onto water-cooled rolls, where it solidifies, and is then rolled, producing sheet directly from the melt. This casting technique has numerous advantages, such as reduction of capital costs, energy consumption, operating costs and scrap rate compared with the conventional direct chill casting route ${ }^{3}$. However, the development of the texture from the as-cast state to the cold rolled and annealed states is still not fully understood. The differential of the present work is that texture is characterized immediately after the twin-roll casting (TRC) process, namely, before any subsequent treatment, i.e., homogenization. And thus it is possible to evaluate the texture evolution from the initiate state as cast. Therefore, in this work, X-ray diffraction was used to investigate the evolution of the texture of cold rolled and recrystallized aluminum alloy in the following conditions: i) as-cast, ii) cold rolled with 67 and $91 \%$ reduction, and iii) subsequent annealing after cold reduction.

\section{Experimental Procedure}

The commercial 3003 aluminum alloy produced by TRC was supplied by the Companhia Brasileira de

*e-mail: julianadepaulamartins@ hotmail.com
Alumínio (CBA) in $7.4 \mathrm{~mm}$ thick strips. Texture analysis was carried out by the back-reflection X-ray goniometric method, using a Rigaku DMAX-2000 diffractometer with $\mathrm{Cu}$ ko radiation. Pole figures (FP) 111, 220, 200 and 311 were measured to determine the orientation distribution functions (ODF).

\section{Results and Discussion}

Figure 1 depicts the ODF, of the as-cast strip surface, showing the presence of the $\{001\}<110>$ component $\left(\varphi_{1}=45^{\circ}, \phi=0^{\circ}\right.$ or $\left.90^{\circ}, \varphi_{2}=0^{\circ}\right)$ known as rotated cube, with an intensity $\mathrm{f}(\mathrm{g})$ of 27.2 .

There was practically no difference between the deformation textures at the two thickness reductions. The sections of the $\phi_{2}$ constants of the cold rolled strip with thickness reduction of 67 and of $91 \%$ (Figure 2) revealed a cold rolled texture typical of aluminum, composed of brass $\{011\}<211>$, $S\{123\}<634>$ and copper $\{112\}<111>$ components along the $\beta$-fiber. Maurice and Driver ${ }^{4}$ found a similar texture on the surface of Al1Mn1Mg alloy, stating that it was similar to the texture obtained by cold rolling of this alloy.

However, the intensity of the copper and $\mathrm{S}$ components showed a subtle difference. At $67 \%$ reduction, the copper component showed $\mathrm{f}(\mathrm{g})=10$ and the $\mathrm{S}$ component showed $f(g)=8$, while at $91 \%$ reduction, the intensities 
$\Phi_{2} 0^{\circ}$

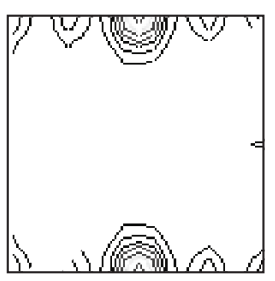

$\Phi_{2} 25^{\circ}$

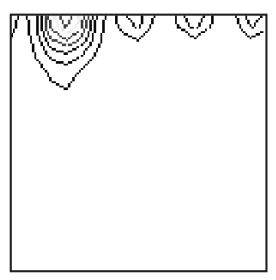

$\Phi_{2} 50^{\circ}$

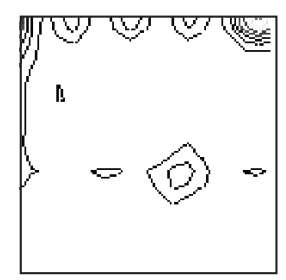

$\Phi_{2} 75^{\circ}$

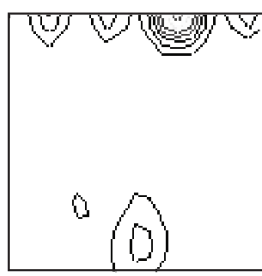

$-27.2$
$\Phi_{2} 5^{\circ}$

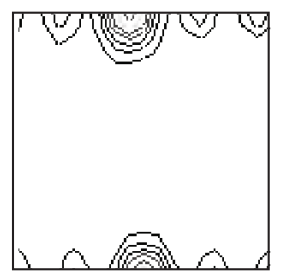

$\Phi_{2} 30^{\circ}$

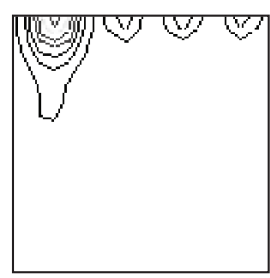

$\Phi_{2} 55^{\circ}$

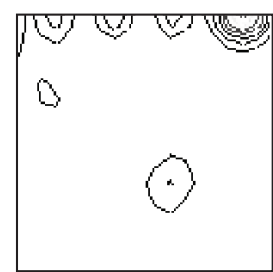

$\Phi_{2} 80^{\circ}$

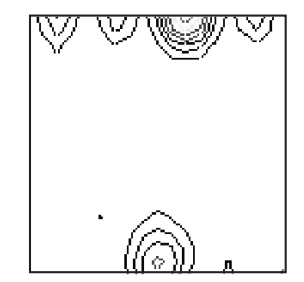

$23.3143-19.4286$
$\Phi_{2} 10^{\circ}$

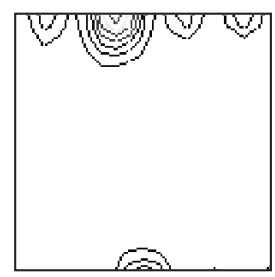

$\Phi_{2} 35^{\circ}$

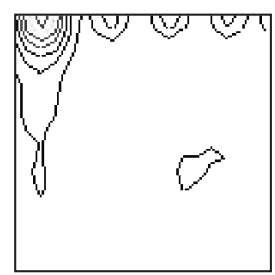

$\Phi_{2} 60^{\circ}$

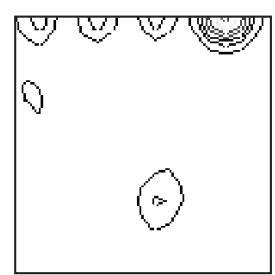

$\Phi_{2} 85^{\circ}$

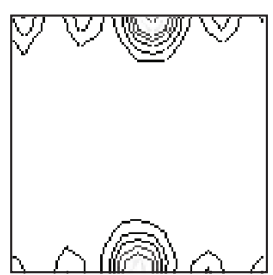

$\Phi_{2} 15^{\circ}$

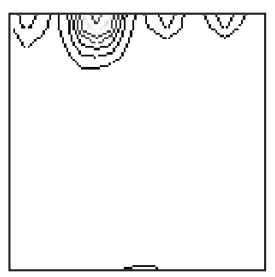

$\Phi_{2} 40^{\circ}$

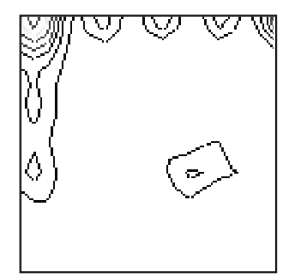

$\Phi_{2} 65^{\circ}$

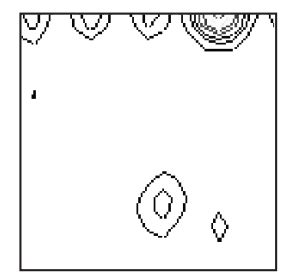

$\Phi_{2} 90^{\circ}$
$\Phi_{2} 20^{\circ}$

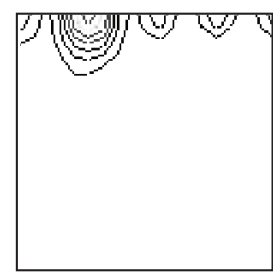

$\Phi_{2} 45^{\circ}$

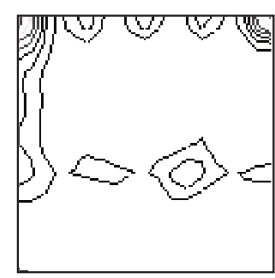

$\Phi_{2} 70^{\circ}$
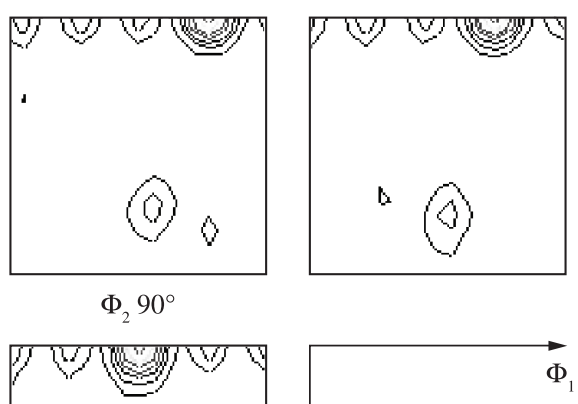

Máx.: 27.2

Figure 1. ODF of the surface of the as-cast sample.

were slightly higher, $\mathrm{f}(\mathrm{g})=12$ and $\mathrm{f}(\mathrm{g})=10$, respectively. Zanget al. ${ }^{5}$ studied the cold rolled texture of $\mathrm{Al} 3004$ alloy and found that the intensity of the copper component increased with increasing reduction, and that the same held true for the $\mathrm{S}$ and brass components, albeit to a lesser extent. However, in the present study, the intensity of the brass component remained constant.

On the other hand, the rotated cube component $\{001\}<110>$ found on the surface of the as-cast strip was absent after cold rolling, suggesting that during rolling the rotated cube texture transforms into a brass, copper and $\mathrm{S}$ type texture ${ }^{5}$. A comparison of the texture of the as-cast TRC strip throughout its thickness and of the cold rolled sample indicated that, at the center of the samples, the textures were similar in terms of components and intensities ${ }^{6}$.

Annealing at higher temperatures often leads to recrystallization, which may generate a completely different preferential crystallographic orientation from that created by plastic deformation. In fact, recrystallization may lead to an absence of texture, to the development of extremely intense texture components, or even to no change in the texture of deformation ${ }^{7}$. For instance, purity high aluminum subjected to high percentages of reduction by rolling may, after annealing, show an extremely intense texture of the $\{100\}<001>$ type (known as cube texture). This change in the deformation texture during recrystallization is consistent with idea that the recrystallization phenomenon is the result of a series of changes in the microstructure of a material in response to heat treatment, with nucleation and growth of new grains. These new grains may have different orientations from those of the deformed microstructure.

The presence of precipitates, particularly of large precipitates (incoherent and nonshearable) that stimulate 


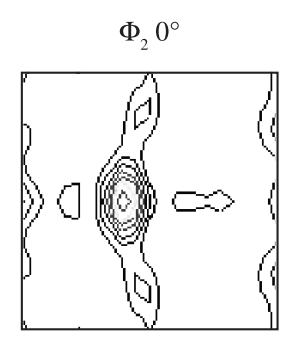

$\Phi_{2} 25^{\circ}$

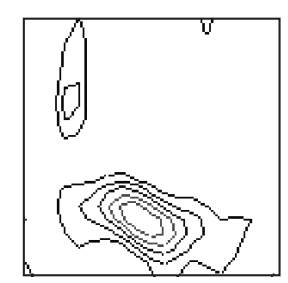

$\Phi_{2} 50^{\circ}$

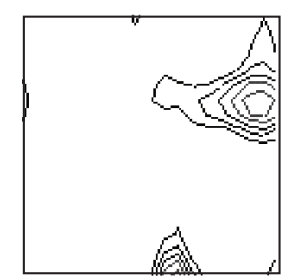

$\Phi, 75^{\circ}$

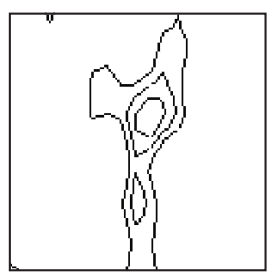

$\Phi_{2} 5^{\circ}$

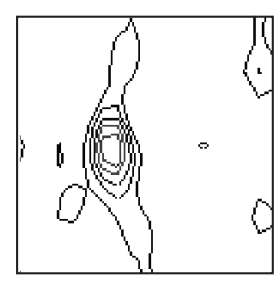

$\Phi_{2} 30^{\circ}$

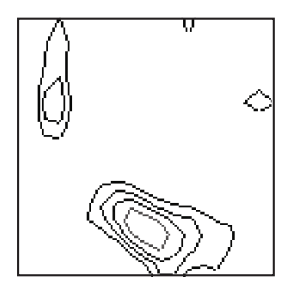

$\Phi_{2} 55^{\circ}$

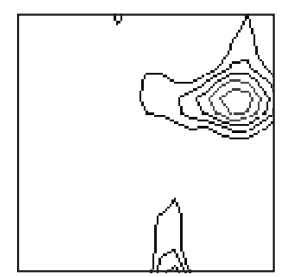

$\Phi_{2} 80^{\circ}$

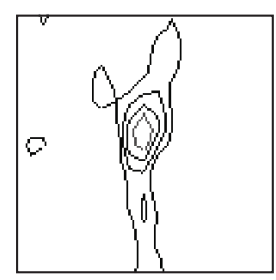

$4-12$
$\Phi_{2} 10^{\circ}$

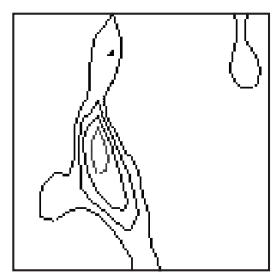

$\Phi_{2} 35^{\circ}$

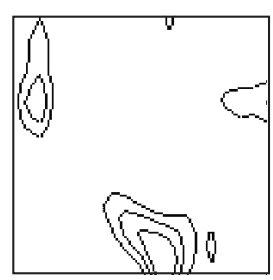

$\Phi_{2} 60^{\circ}$

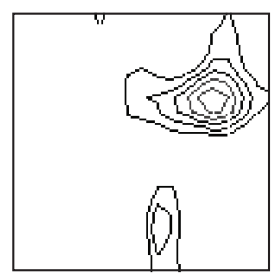

$\Phi_{2} 85^{\circ}$

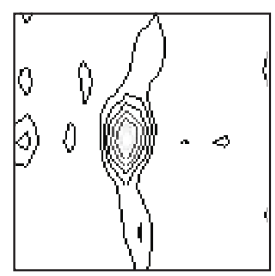

$\Phi_{2} 15^{\circ}$

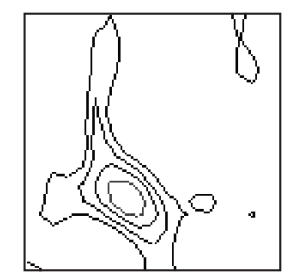

$\Phi_{2} 40^{\circ}$

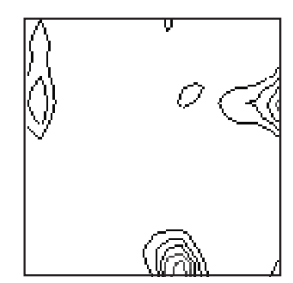

$\Phi_{2} 65^{\circ}$

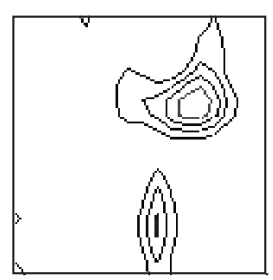

Ф $90^{\circ}$

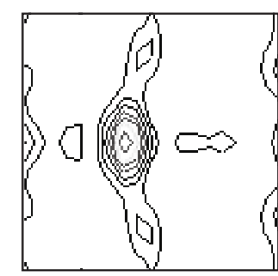

$\Phi$
$\Phi_{2} 20^{\circ}$

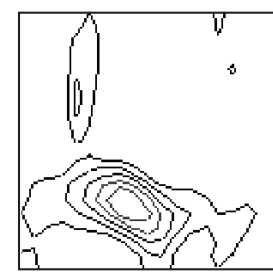

$\Phi_{2} 45^{\circ}$

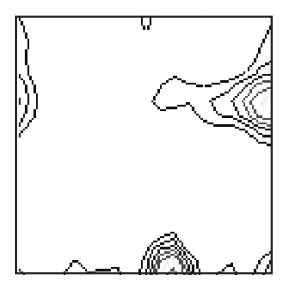

$\Phi_{2} 70^{\circ}$
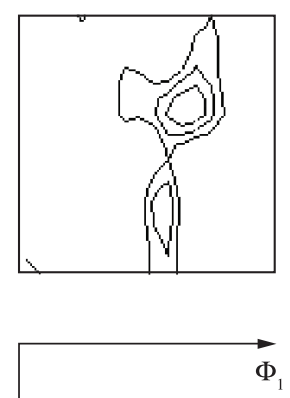

Máx.: 14

Figure 2. ODF of the surface of the cold rolled samples with 67 and $91 \%$ reduction.

recrystallization nucleation, favors the presence of random texture, i.e., absence of texture, because large precipitates favor recrystallization nucleation around them. Cube recrystallization textures are generally strengthened by high cold reductions and high recrystallization temperatures. Moreover, annealing textures that may contain the cube orientation promote pronounced earing, namely, at $0 / 90^{\circ}$, while rolling texture components (S, Brass and Copper) promote earing at $45^{\circ} / 135^{\circ[8]}$. Since $90^{\circ}$ earing is more harmful and more easily causes defects during deep drawing, the thermomechanical process is designed so that the hot band undergoes a reduction large enough to obtain a small degree of $45^{\circ}$ earing in the final gauge sheet. Although $45^{\circ}$ earing is better than $90^{\circ}$ earing for deep drawing, minimizing the earing is always the object.
After annealing the sample with $91 \%$ reduction at $400{ }^{\circ} \mathrm{C}$, its texture presented components retained from the rolling texture, i.e., the cube component and the $\{001\}<310>$ component, as indicated in Figure 3. And the level of intensity of the retained rolling components (copper, brass and $\mathrm{S}$ ) known as $\beta$ fibers is comparable to that of the rolled condition. Only the brass component presented a slightly lower intensity in the recrystallized condition. Benum and $\mathrm{Nes}^{9}$ investigated the effect of precipitation on the development of cubeoriented grains at recrystallization. They found that the cube texture predominated at $275{ }^{\circ} \mathrm{C}$, while at $400{ }^{\circ} \mathrm{C}$ they detected components retained from the rolling texture as well as the cube texture. These authors concluded that, in response to increased temperature, the change from cube type to $\beta$ fiber type texture was induced by precipitation. 
$\Phi_{2} 0^{\circ}$

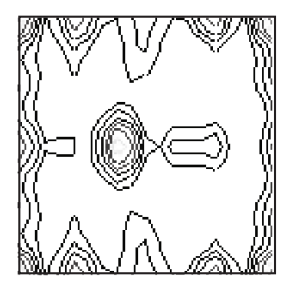

$\Phi_{2} 25^{\circ}$

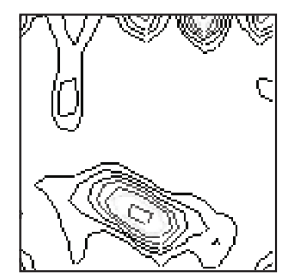

$\Phi_{2} 50^{\circ}$

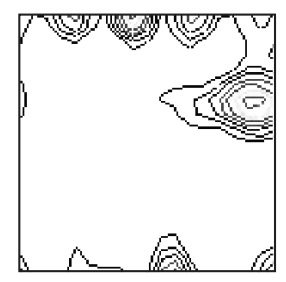

$\Phi_{2} 75^{\circ}$

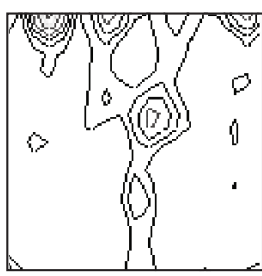

$\Phi_{2} 10^{\circ}$

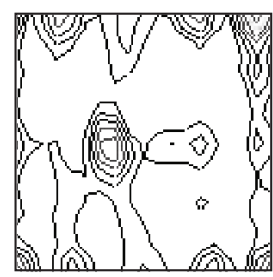

$\Phi_{2} 30^{\circ}$

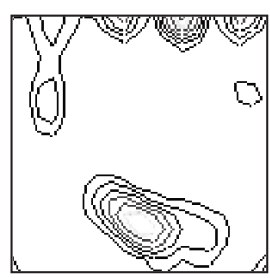

$\Phi_{2} 55^{\circ}$

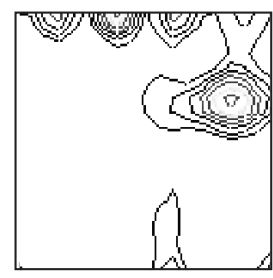

$\Phi_{2} 80^{\circ}$

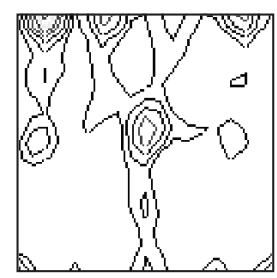

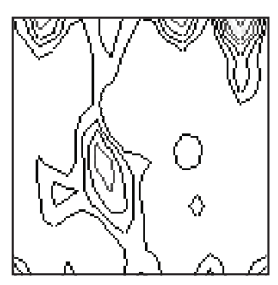

$\Phi_{2} 35^{\circ}$

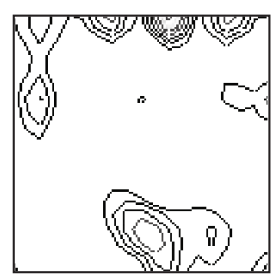

$\Phi_{2} 60^{\circ}$

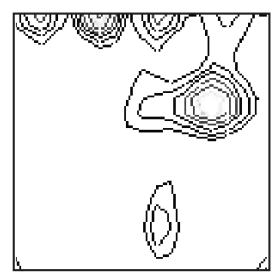

$\Phi_{2} 85^{\circ}$

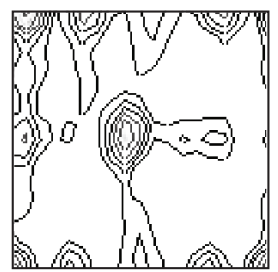

$\Phi_{2} 15^{\circ}$

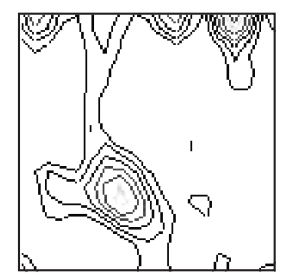

$\Phi_{2} 40^{\circ}$

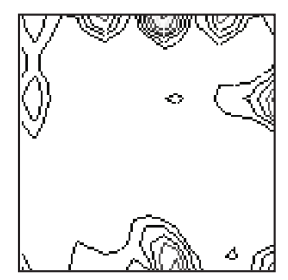

$\Phi_{2} 65^{\circ}$

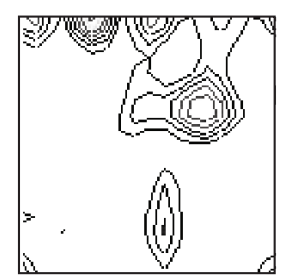

$\Phi_{2} 90^{\circ}$
$\Phi_{2} 20^{\circ}$

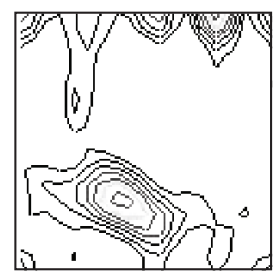

$\Phi_{2} 45^{\circ}$

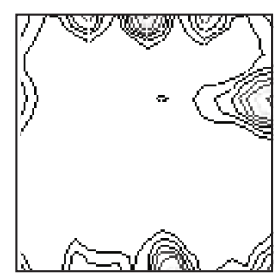

$\Phi_{2} 70^{\circ}$
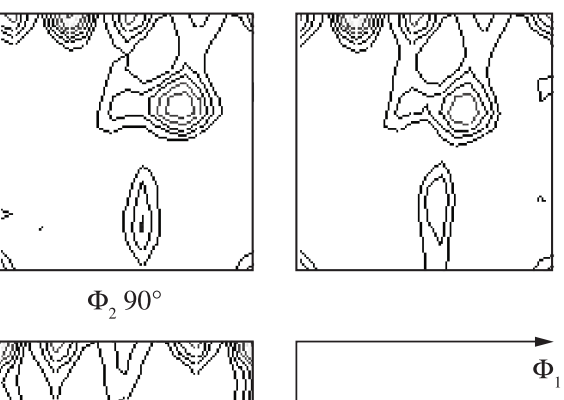

Máx.: 11.5

\section{$-11.5-9.8673-8.2143-6.5714-4.9286-3.2857-1.6429$}

Figure 3. ODF of the sample annealed at $400{ }^{\circ} \mathrm{C}$ for 1 hour after $91 \%$ reduction.

Doherty ${ }^{7}$ stated that cold rolled and recrystallized commercially pure aluminum contains a significant retained rolling texture. According to this author, an aluminum alloy containing large iron-rich constituents of 1 to $2 \mu \mathrm{m}$ will present differences in orientation in the deformed zone with sizes equal to or more than twice that size; hence, this deformation zone will be thicker than the deformed band. This deformation zone will increase the difference in deformation-band orientation, enabling new grains from the orientation retained from rolling to grow through deformation bands. Therefore, the orientation pinning model, which is characterized by blocking of nucleus growth due to the low mobility of low angle grains, is weak for commercially pure cold rolled aluminum, explaining the strong rolling texture retained during recrystallization.

Figure 4 depicts the ODF of the rolled sample with $67 \%$ reduction recrystallized for 1 hour at $400{ }^{\circ} \mathrm{C}$. It is possible to notice the absence of texture retained from rolling. In this case, the texture presents both the $\{001\}<310>$ and cube components, with the first showing higher intensity. This component is known as cube ${ }_{\mathrm{ND}}$, i.e., rotation of the cube orientation around the normal $\{001\}<u v 0>$ direction, which is visible along $\varphi_{1}$, with $\varphi_{2}=\phi=0^{\circ}$ or $90^{\circ}$.

The intensity of a material's texture is represented by the $\mathrm{J}$ index proposed by Bunge ${ }^{10}$. Samples without texture show $\mathrm{J}=1$, while a monocrystal shows $\mathrm{J} \rightarrow \infty$. In this work, the $\mathrm{J}$ index of the sample that underwent $91 \%$ reduction was $\mathrm{J}=23.8$, while that of the sample with $67 \%$ reduction showed $\mathrm{J}=31.3$.

\section{Conclusions}

The $\{001\}<110>$ rotated cube texture predominated on the as-cast surface, transforming into a brass, copper and $\mathrm{S}$ type texture during the cold rolling process. 
$\Phi_{2} 0^{\circ}$

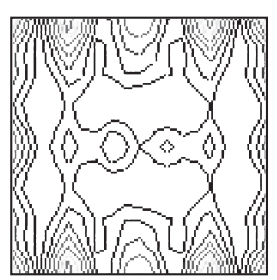

$\Phi_{2} 25^{\circ}$

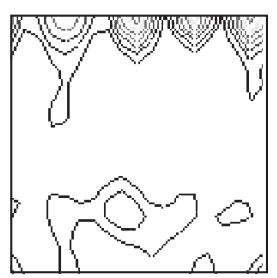

$\Phi_{2} 50^{\circ}$

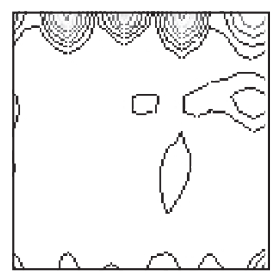

$\Phi, 75^{\circ}$

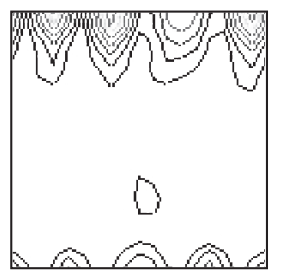

$\Phi_{2} 5^{\circ}$

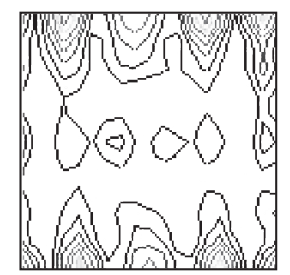

$\Phi_{2} 30^{\circ}$

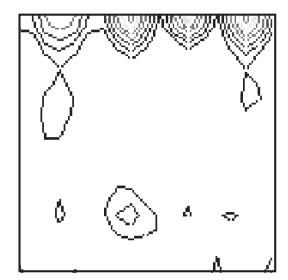

$\Phi_{2} 55^{\circ}$

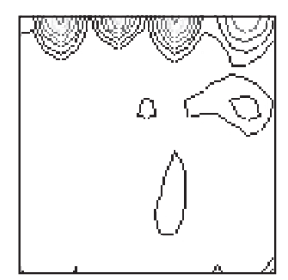

$\Phi_{2} 80^{\circ}$

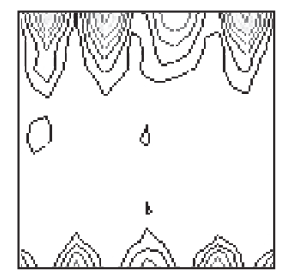

$\Phi_{2} 10^{\circ}$

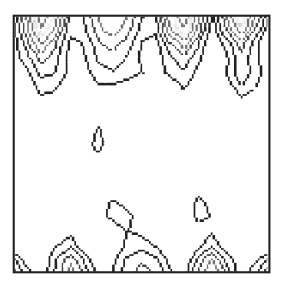

$\Phi_{2} 35^{\circ}$

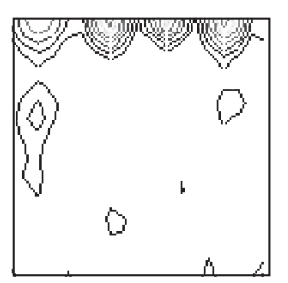

$\Phi_{2} 60^{\circ}$

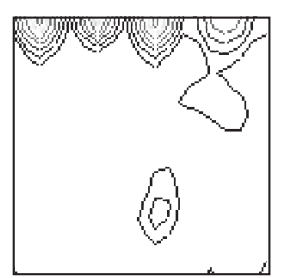

$\Phi_{2} 85^{\circ}$

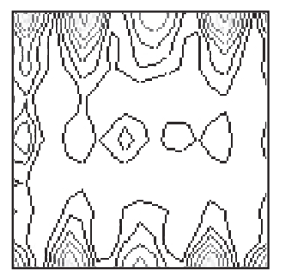

$\Phi_{2} 15^{\circ}$

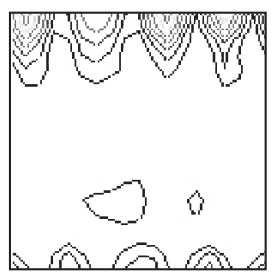

$\Phi_{2} 40^{\circ}$

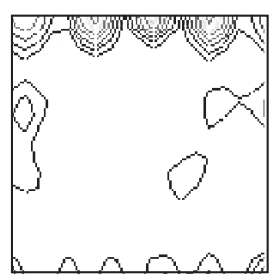

$\Phi_{2} 65^{\circ}$

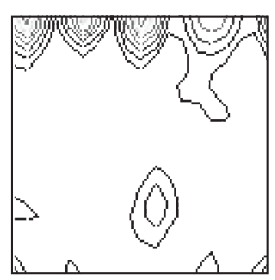

$\Phi_{2} 90^{\circ}$

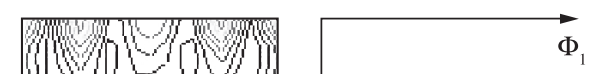

Máx.: 13.1

$$
\begin{array}{llllllll}
\hline & 13.1 & 11.2280 & -9.3571 & -7.4857 & -5.6143 & -3.7429 & -1.8714 \\
\hline
\end{array}
$$

Figure 4. ODF of the sample annealed at $400{ }^{\circ} \mathrm{C}$ for 1 hour after $67 \%$ reduction.

After cold rolling, the strips revealed a texture composed of $\{011\}<211>$ brass, $\{123\}<634>S$ and $\{112\}<111>$ copper components along the $\beta$ fiber.

The higher cold rolling reduction $(91 \%)$ and annealing resulted in a recrystallized texture consisting of a combination of cube (typical of recrystallization) and brass, copper and $\mathrm{S}$ type (typical of deformation texture) components. This combination produces the best results to minimize the earing effect. In contrast, the lower cold rolling reduction $(67 \%)$ and annealing resulted only in cube and cube ${ }_{\mathrm{ND}}$ components after recrystallization.

\section{Acknowledgement}

This work is supported by the Fundação de Amparo à Pesquisa do Estado de São Paulo (FAPESP) through Grant 02/03252-6. 


\section{References}

1. Haga T and Suzuki S. A high speed twin roll caster for aluminum alloy strip. Journal of Materials Processing Technology. 2001; 113:291-295. http://dx.doi.org/10.1016/ S0924-0136(01)00673-2

2. Yun M,Lokyer S and Hunt JD. Twin roll casting of aluminiumalloys. Materials Science and Engineering: A. 2000; 280A:116-123. http://dx.doi.org/10.1016/S0921-5093(99)00676-0

3. Gras C, Meredith M and Hunt JD. Microstructure and texture evolution after twin roll casting and subsequent cold rolling of Al-Mg-Mn aluminium alloys. Journal of Materials Processing Technology. 2005; 169:156-163. http://dx.doi.org/10.1016/j. jmatprotec.2005.03.034

4. Maurice CI and Driver JH. Hot rolling textures of f.c.c. metals Part I. Experimental results on Al single and polycrystals. Acta Materialia. 1997; 45(11):4627-4638. http://dx.doi.org/10.1016/ S1359-6454(97)00115-8

5. Zhang DF, Jiang XP, Hu ZC, Wang F and Zuo F. Rolling and Annealing Texture of 3004 Aluminium Alloy. Mater. Sci. Forum 2002; 408-412:1477-1482. http://dx.doi.org/10.4028/ www.scientific.net/MSF.408-412.1477
6. Martins JP, Carvalho ALM and Padilha AF. Microstructure and texture assessment of $\mathrm{Al}-\mathrm{Mn}-\mathrm{Fe}-\mathrm{Si}$ (3003) aluminum alloy produced by continuous and semicontinuous casting processes. Journal of Materials Science. 2009; 44:2966-2976. http:// dx.doi.org/10.1007/s10853-009-3393-z

7. Doherty RD. Recrystallization and texture. Progress in Materials Science. 1997; 42:39-58. http://dx.doi.org/10.1016/ S0079-6425(97)00007-8

8. Zhao Z, Mao W, Roters F and Raabe D. A texture optimization study for minimum earing in aluminium by use of a texture component crystal plasticity finite element method. Acta Materialia. 2004; 52:1003-1012. http://dx.doi.org/10.1016/j. actamat.2003.03.001

9. Benum $\mathrm{S}$ and Nes E. Strength variability in alumina fiberreinforced aluminum matrix composites. Acta Materialia. 1997; 45(11):4593-4602.

10. Bunge HJ. Texture analysis in materials science mathematical methods. 3th ed. Butterworths; 1982. 